\title{
Transfer of discrimination from solid objects to pictures by pigeons: A test of theoretical models of pictorial perception
}

\author{
PATRICK A. CABE \\ Cornell University, Ithaca, New York 14850
}

\begin{abstract}
Various authors have suggested that learning associations between objects and pictures is a necessary condition for the perception of pictures. If so, then animals, never exposed to situations in which those associations might be learned, should not show transfer between objects and pictures. In this investigation, pigeons trained to discriminate between two solid objects were retrained with reinforcement reversal on either the objects themselves or photographs, line drawings, or silhouettes of the objects. Significant negative transfer indicated object-photograph and object-silhouette equivalence, but no transfer was found to line drawings. Positive transfer to photographs was also demonstrated. Transfer did not appear to be a function of object-picture confusability.
\end{abstract}

Discussions of the perception of pictures have generally focused on the issue of whether or not the ability to recognize objects in pictures depends on learned associations between objects and pictures (Gibson, 1971; Goodman, 1968; Hagen, 1974; Hochberg \& Brooks, 1962; Miller, 1973). The putative falsifying experiments for such a position have involved subject populations which presumably have had no, or limited, opportunity to learn object-picture associations, either due to the conditions in the subjects' normal environment or to imposed isolation from such experience. Thus, various researchers have investigated object-picture equivalence with infants (Hochberg \& Brooks, 1962) and with individuals from cultures not having representational pictorial art traditions (Miller, 1973).

The rationale supporting cross-cultural and infant studies of pictorial perception suggests similar studies with nonhuman subjects. Responses to pictorial stimulus materials with nonhuman subjects have been investigated (e.g., Butler, 1961; Hermstein \& Loveland, 1964; Lubow, 1974), but few have tested object-picture equivalence in a direct way, and those with mixed results: Davenport and Rogers (1971) reported a high degree of spontaneous object-picture equivalence for great apes, using a cross-modal matching-to-sample technique.

These experiments are portions of a thesis submitted for the degree Doctor of Philosophy in psychology at Cornell University. I thank the members of my doctoral committee, Eleanor J. Gibson, the late Eric H. Lenneberg, and William C. Dilger, for their encouragement and advice in this work, $I$ am indebted to Andre Gobert, manager of the Cornell Pigeon Loft, for supplying experimental animals and much helpful comment. I acknowledge the technical assistance of Suellen Cabe in performing these experiments. Portions of this work were done while the author was an NIMH predoctoral fellow at Cornell University. The author is now at Saint Augustine's College, Raleigh, North Carolina 27611. Reprint requests should be directed to him at Route 3, Box 163A, Apex, North Carolina 27502.
Zimmermann and Hochberg $(1970,1971)$ assert that infant rhesus monkeys also show transfer of a discriminative response between objects and pictures. But Klopfer (1971) found no object-picture equivalence for ducklings in an imprinting task. Collectively, these results suggest two things: that learning is not a prerequisite for object-picture equivalence in (some) animals and that there may be an interesting taxonomic difference (i.e., between primate and nonprimate species) in the ability to make use of information in pictorial displays.

The present experiments were designed to show that learned object-picture associations and object-picture confusability are not necessary conditions for the perception of several kinds of pictures by a nonprimate species, the domestic homing pigeon. Evidence for spontaneous object-picture transfer and for objectpicture discriminability would argue against theories invoking learned object-picture associations and for some other theory (or for the need for some other theory), perhaps based on some form of optical equivalence, such as Gibson's (1971) information equivalence theory.

It was predicted that pigeons trained to discriminate two solid objects would show significant spontaneous transfer to black-and-white photographs, to line drawings, and to white-on-black silhouettes of those objects, that the degree of transfer would not differ from that shown to the solid objects themselves (under reversal conditions), and that the objects could be shown to be discriminably different from their respective photographs, drawings, and silhouettes.

\section{GENERAL METHODS}

The following general methods and procedures were used in all experiments; differences were primarily in stimulus displays used and are described as needed for each experiment. 


\section{Subjects}

Sixteen adult homing pigeons from the Cornell University pigeon loft, a colony maintained for studies of homing, were used. All were experimentally naive for the purposes of the experiments conducted. The exact experimental histories of the birds were not ascertained, but none of them had previously been used in operant conditioning or discrimination studies. Birds were maintained on ad-lib water and grit, at approximately $80 \%$ of their free-feeding weights throughout the experiments.

\section{Apparatus}

A standard singlekey pigeon operant conditioning chamber (Lehigh Valley Electronics Model 132-02), modified for the purposes of the experiments, was used. The response key was $2.5 \mathrm{~cm}$ in diameter, of transparent Plexiglas. The key was replaced at approximately weekly intervals to avoid possible deleterious effects of pits or scratches on the birds' view of the objects. A rectangular sheet metal hood $(5.1 \times 5.1 \times 3.2 \mathrm{~cm}$ wide, open on the front and bottom) was attached to the response panel around the key. The function of the hood was to standardize the views all birds had of the displays by minimizing lateral head movements and by reducing idiosyncratic positions relative to the key.

A sheet metal tunnel $(10.8 \mathrm{~cm}$ wide $\times 13.3 \mathrm{~cm}$ high $\mathrm{x}$ $22.2 \mathrm{~cm}$ long) was centered on the key behind the response panel. A 1.9 -cm-thick plywood block was inserted in the floor of the tunnel. Mounting blocks for the stimulus displays butted against this floor block inside the tunnel. A microswitch mounted in the side of the tunnel near the sheet metal floor sensed the positive (reinforced) or negative (nonreinforced) display as the display mounting block either depressed the switch or not. Two small pilot lamps, mounted above and to the left and right of the key inside the tunnel, illuminated the displays. Subjects then viewed the displays in the tunnel through the transparent response key.

Relay logic and recording equipment was used. The ventilation blower in the chamber and low level of white noise provided masking noise. The level of masking noise was not measured, but control experiments indicated that extraneous noises from the equipment and procedures did not contribute to the discriminations observed.

\section{Stimulus Materials}

A number of different displays were used. The first of these was a pair of solid objects, a rectangular block $(5.7 \mathrm{~cm}$ square $x$ $1.9 \mathrm{~cm}$ thick) and a cross $(5.7 \mathrm{~cm}$ tall $\times 5.7 \mathrm{~cm}$ wide $x 1.9 \mathrm{~cm}$ thick, with $1.9-\mathrm{cm}$ square arms), centered, respectively, on 1.9-cm-thick base blocks at a $45^{\circ}$ angle to the back edges of the blocks. A Masonite back panel was screwed to the back of each of the base blocks. Base blocks and back panels were painted navy gray. The objects themselves were painted flat white. The mounting blocks and back panels without the objects were used in one phase of Experiment II and in Experiment III.

Pictorial displays were of three types: black-and-white photographs, made under lighting conditions approximating those in the tunnel; perspective line drawings, made by hand with the aid of a straight edge, inked with black drawing ink, and photographed; and white-on-black silhouettes (photograms), made by masking sheets of photographic enlarging paper with square or cross-shaped pieces of thin cardboard and exposing the paper. All the pictorial displays were produced on Kodak Polycontrast N-surface photographic enlarging paper, at a reproduction ratio of $1: 1$. The pictures were glued to back panels and inserted into slots cut across the center of mounting blocks.

\section{Procedure}

Pretraining. On being brought into the laboratory, the birds were given free food, water, and grit for several days, to establish free-feeding weight, and then deprived to approximately
$80 \%$ of that weight. Concurrent with deprivation, birds were adapted to the apparatus and trained to peck the clear key, initially without the hood around it and later with the hood in place. The tunnel was empty during pretraining. All pretraining was done under continuous reinforcement, and discrimination training started when all the birds would readily peck the hooded key.

Discrimination training. The same procedure was followed in all phases of all experiments. Training consisted of 48 daily trials, each trial consisting of a $30-\mathrm{sec}$ stimulus display presentation followed by a 10-sec blackout. A successive discrimination paradigm was used, with the positive and negative displays counterbalanced. A variable-interval 10 -sec schedule of reinforcement was in force for all trials. Birds ate only in the experimental apparatus; reinforcement was a $5 \mathrm{sec}$ access to mixed grain. Displays were changed by hand during the blackout following random sequences published by Fellows (1967). Cumulative responses for each trial were recorded.

Criteria for discrimination were (a) $75 \%$, or better, of all responses to the reinforced display for 3 consecutive days, and (b) five or fewer no-go errors (a no-go error being a trial in which reinforcement was available but no responses were made) for 3 (not necessarily consecutive) days.

Given that negative transfer was ultimately of interest, the $75 \%$ criterion and the VI $10-\mathrm{sec}$ schedule of reinforcement are both conservative, in that more stringent requirements would have been expected to produce greater persistence of response to a previously reinforced display under reversal of reinforcement.

\section{EXPERIMENT I}

\section{Design and Procedure}

The predictions outlined above were tested in a three-stage experiment, as shown in Table 1. In Stage I of the experiment, all birds were trained to discriminate between the solid objects (designated Object $A$ and Object B), with the two objects counterbalanced as indicated. In Stage II, all birds were shifted to new discrimination problems. For the object group (the control group), the new problem was a reversal of the Siage I problem, using the original solid objects. The other groups learned to discriminate between black-and-white photographs (photo group), perspective line drawings (drawing group), or white-on-black silhouettes (silhouette group) of the original, Stage I, solid objects. The Stage I reinforcement contingency was reversed for all subjects in Stage II. Thus, birds reinforced for responding to Object $A$ in Stage I were required to respond in Stage II to either the solid Object B, photograph of Object B, drawing of Object $B$, or silhouette of Object $B$. The indicator of object-picture equivalence, then, was negative transfer, the degree to which responses to the object reinforced in Stage I persisted in Stage II.

Stage II allowed group comparisons between the solid objects and pictorial representations. Differences between the numbers of responses to the representations and to the solid objects would indicate the degree of similarity between the representations and the solid objects. Nonsignificant differences would suggest a high degree of equivalence.

In Stage III, the discrimination between the pictures and the objects pictured was tested: if, in Stage II, a bird had been trained to respond to a photograph of Object $A$ vs. a photograph of Object B, in Stage III that bird was required to respond to the photograph of Object A vs. the solid Object A. The importance of Stage III was in showing that transfer could occur when confusion between the solid object and its picture was unlikely.

Discrimination and transfer training proceeded as described. Stage II training started on the day after attainment of criterion on Stage I, and Stage III began immediately after completion of Stage II. 
Table 1

Design of Experiment I

\begin{tabular}{|c|c|c|c|c|c|c|}
\hline \multirow[b]{2}{*}{ Experimental Groups } & \multicolumn{2}{|c|}{$\begin{array}{c}\text { Stage I } \\
\text { Initial } \\
\text { Discrimination }\end{array}$} & \multicolumn{2}{|c|}{$\begin{array}{c}\text { Stage II } \\
\text { Transfer Reversal } \\
\text { Condition }\end{array}$} & \multicolumn{2}{|c|}{$\begin{array}{c}\begin{array}{c}\text { Stage III } \\
\text { Post- } \\
\text { Discrimination }\end{array} \\
\end{array}$} \\
\hline & $\mathrm{s}^{\mathrm{D}}$ & $s^{\Delta}$ & $\mathrm{s}^{\mathrm{D}}$ & $\mathrm{S}^{\Delta}$ & $\mathrm{s}^{\mathrm{D}}$ & $s^{\Delta}$ \\
\hline $\begin{array}{l}\text { Object Group } \\
\text { (Control) }\end{array}$ & $\begin{array}{l}\text { Object A } \\
\text { Object B }\end{array}$ & $\begin{array}{l}\text { Object B } \\
\text { Object A }\end{array}$ & $\begin{array}{l}\text { Object B } \\
\text { Object A }\end{array}$ & $\begin{array}{l}\text { Object A } \\
\text { Object B }\end{array}$ & Object A & \\
\hline Photo Group & $\begin{array}{l}\text { Object A } \\
\text { Object B }\end{array}$ & $\begin{array}{l}\text { Object B } \\
\text { Object A }\end{array}$ & $\begin{array}{l}\text { Photo B } \\
\text { Photo A }\end{array}$ & $\begin{array}{l}\text { Photo A } \\
\text { Photo B }\end{array}$ & $\begin{array}{l}\text { Photo B } \\
\text { Photo A }\end{array}$ & $\begin{array}{l}\text { Object B } \\
\text { Object A }\end{array}$ \\
\hline Drawing Group & $\begin{array}{l}\text { Object A } \\
\text { Object B }\end{array}$ & $\begin{array}{l}\text { Object B } \\
\text { Object A }\end{array}$ & $\begin{array}{l}\text { Drawing B } \\
\text { Drawing A }\end{array}$ & $\begin{array}{l}\text { Drawing A } \\
\text { Drawing B }\end{array}$ & $\begin{array}{l}\text { Drawing B } \\
\text { Drawing A }\end{array}$ & $\begin{array}{l}\text { Ofject B } \\
\text { Object A }\end{array}$ \\
\hline Silhouette Group & $\begin{array}{l}\text { Object A } \\
\text { Object B }\end{array}$ & $\begin{array}{l}\text { Object B } \\
\text { Object A }\end{array}$ & $\begin{array}{l}\text { Silhouette B } \\
\text { Silhouette A }\end{array}$ & $\begin{array}{l}\text { Silhouette A } \\
\text { Silhouette B }\end{array}$ & $\begin{array}{l}\text { Silhouette B } \\
\text { Silhouette A }\end{array}$ & $\begin{array}{l}\text { Object B } \\
\text { Object A }\end{array}$ \\
\hline
\end{tabular}

\section{Results}

Results for individual birds and for the four experimental groups on the last Stage I and the first Stage II days are summarized in Table 2 .

Total responses to the members of the display pairs on the last criterion day of Stage I and the first Stage II transfer day were compared using a 2 (Days) by 4 (Groups) by 2 (Objects) repeated measures analysis of variance; a conservative degrees of freedom $(1, n-1=3)$ was adopted for all tests, due to the small number of measures (Winer, 1962).

Total responses did not change as a result of the display change and/or reinforcement reversal, since the Days effect was nonsignificant $(F=1.20, p>.05)$ and the Days by Groups interaction was nonsignificant
$(F=1.32, p>.05)$. Negative transfer (i.e., maintained responses to the reinforced Stage I object), however, did occur, since a significant Objects effect was found $(F=198.36, p<.01)$. Differential negative transfer across display types was suggested by the significant Days by Objects interaction $(F=40.0, p<.01)$.

Total responses to the Stage I SD and $S \Delta$ on the first Stage II day were analyzed in a 4 (Groups) by 4 (Quarter Sessions) by 2 (Objects) repeated measures analysis of variance, again adopting conservative degrees of freedom. The session was broken down by quarters to assess reversal leaming effects within the first Stage II session.

That discrimination between the members of the display pairs occurred was shown by the significant Objects

Table 2

Means and Standard Deviations of Trial-Wise Responses by Individual Subjects on the Last Criterion Day of Stage 1 (Initial Object Discrimination) and the First Day of Stage II (Object or Picture Transfer), Experiment I

\begin{tabular}{|c|c|c|c|c|c|c|c|c|}
\hline \multirow[b]{3}{*}{ Bird } & \multicolumn{4}{|c|}{ Last Criterion Day-Stage I } & \multicolumn{4}{|c|}{ First Transfer Day-Stage II* } \\
\hline & \multicolumn{2}{|c|}{$\mathbf{s}^{\mathbf{D}}$} & \multicolumn{2}{|c|}{$\mathrm{s}^{\Delta}$} & \multicolumn{2}{|c|}{$\mathrm{s}^{D}$} & \multicolumn{2}{|c|}{$\mathbf{s}^{\Delta}$} \\
\hline & $\overline{\mathbf{x}}$ & S.D. & $\overline{\mathbf{X}}$ & S.D. & $\bar{x}$ & S.D. & $\overline{\mathbf{X}}$ & S.D. \\
\hline & \multicolumn{8}{|c|}{ Object Group } \\
\hline \multirow[t]{2}{*}{$\begin{array}{l}20 \\
22 \\
27 \\
34\end{array}$} & $\begin{array}{l}54.25 \\
45.42 \\
19.58 \\
43.21\end{array}$ & $\begin{array}{r}10.54 \\
14.05 \\
6.54 \\
21.13\end{array}$ & $\begin{array}{r}8.92 \\
3.79 \\
.13 \\
1.21\end{array}$ & $\begin{array}{r}5.80 \\
6.49 \\
.45 \\
1.64\end{array}$ & $\begin{array}{r}23.46 \\
8.96 \\
.75 \\
15.29\end{array}$ & $\begin{array}{l}9.54 \\
8.56 \\
2.69 \\
8.84\end{array}$ & $\begin{array}{l}44.79 \\
40.54 \\
12.75 \\
42.71\end{array}$ & $\begin{array}{r}23.42 \\
26.91 \\
8.32 \\
30.13\end{array}$ \\
\hline & \multicolumn{8}{|c|}{ Photo Group } \\
\hline \multirow[t]{2}{*}{$\begin{array}{l}24 \\
26 \\
28 \\
29\end{array}$} & $\begin{array}{l}31.42 \\
41.58 \\
47.63 \\
61.83\end{array}$ & $\begin{array}{l}19.44 \\
12.57 \\
14.78 \\
12.61\end{array}$ & $\begin{array}{l}1.00 \\
1.88 \\
4.63 \\
3.17\end{array}$ & $\begin{array}{l}2.62 \\
2.42 \\
6.59 \\
3.68\end{array}$ & $\begin{array}{r}7.38 \\
10.17 \\
19.38 \\
21.00\end{array}$ & $\begin{array}{r}6.98 \\
8.14 \\
8.10 \\
14.53\end{array}$ & $\begin{array}{l}26.58 \\
27.92 \\
37.58 \\
33.88\end{array}$ & $\begin{array}{l}22.80 \\
21.94 \\
21.30 \\
26.30\end{array}$ \\
\hline & \multicolumn{8}{|c|}{ Drawing Group } \\
\hline \multirow[t]{2}{*}{$\begin{array}{l}18 \\
21 \\
33 \\
35\end{array}$} & $\begin{array}{l}42.25 \\
48.71 \\
25.79 \\
27.25\end{array}$ & $\begin{array}{r}13.72 \\
18.71 \\
9.18 \\
9.33\end{array}$ & $\begin{array}{l}3.42 \\
1.54 \\
2.67 \\
1.25\end{array}$ & $\begin{array}{l}3.32 \\
5.06 \\
2.44 \\
2.01\end{array}$ & $\begin{array}{l}21.17 \\
15.38 \\
11.54 \\
20.50\end{array}$ & $\begin{array}{r}11.65 \\
11.12 \\
6.26 \\
7.51\end{array}$ & $\begin{array}{l}23.42 \\
22.33 \\
12.04 \\
22.96\end{array}$ & $\begin{array}{r}13.35 \\
18.74 \\
6.56 \\
13.94\end{array}$ \\
\hline & \multicolumn{8}{|c|}{ Silhouette Group } \\
\hline $\begin{array}{l}19 \\
30 \\
31 \\
36\end{array}$ & $\begin{array}{l}91.58 \\
35.46 \\
55.08 \\
41.79\end{array}$ & $\begin{array}{r}21.20 \\
9.39 \\
12.53 \\
6.45\end{array}$ & $\begin{array}{r}8.46 \\
.08 \\
6.13 \\
7.38\end{array}$ & $\begin{array}{r}11.78 \\
.41 \\
4.80 \\
17.41\end{array}$ & $\begin{array}{r}19.54 \\
3.04 \\
17.17 \\
14.00\end{array}$ & $\begin{array}{r}21.28 \\
4.32 \\
12.39 \\
17.24\end{array}$ & $\begin{array}{l}33.71 \\
20.25 \\
40.67 \\
38.00\end{array}$ & $\begin{array}{l}34.17 \\
15.15 \\
28.11 \\
22.39\end{array}$ \\
\hline
\end{tabular}

${ }^{*} S^{\Delta}$ in Stage II was the object or picture of the object reinforced in Stage $I$. 
Table 3

Summary of Mann-Whitney U Tests on Responses in First Transfer Session to Individual Presentations of $S^{D}$ and $S^{\Delta}$, Experiment I

\begin{tabular}{lccl}
\hline Bird & $\mathrm{U}$ & $\mathrm{z}$ & \multicolumn{1}{c}{$\mathrm{p}^{*}$} \\
\hline \multicolumn{4}{c}{ Object Group } \\
20 & 101.5 & 3.85 & .00006 \\
22 & 64 & 4.62 & .0000019 \\
27 & 30.5 & 5.31 & .000000055 \\
34 & 138.5 & 3.08 & .00103 \\
& & Photo Group & \\
24 & 119 & 3.48 & .00025 \\
26 & 108.5 & 3.70 & .00011 \\
28 & 125 & 3.36 & .00039 \\
29 & 217 & 1.46 & .0716 \\
& & Drawing Group & \\
18 & 255.5 & .67 & .251 \\
21 & 246.5 & .86 & .196 \\
33 & 295.5 & -.15 & .561 \\
35 & 244 & .89 & .182 \\
& & & \\
19 & 182 & Silhouette Group & \\
30 & 96.5 & 2.19 & .014 \\
31 & 149.5 & 3.95 & .000039 \\
36 & 112.5 & 2.86 & .0021 \\
\hline
\end{tabular}

* One-tailed test, in the direction of negative transfer predicted by the initial object discrimination.

effect $(F=142.21, p<.01)$. That the reversal was being learned during the first Stage Il session was indicated by the significant Quarter Session by Objects interaction $(F=15.84, p<.05)$.

The important finding, differential transfer among display types, was suggested by the significant Groups by Objects interaction $(F=11.16, p<.05)$. The total number of responses emitted to the members of the display pair by the object group (the control group) was significantly greater than the totals emitted by the drawing group but not by the photo or the silhouette groups when appropriate individual comparisons were made. That is, black-and-white photographs and white-on-black silhouettes were seen as equivalent to the solid objects, but line drawings were not.

All four of the birds in the object group, all four in the silhouette group, three of four in the photo group, but none of the animals in the drawing group, showed negative transfer, in that the numbers of responses to individual presentations of the members of the display pairs in the first Stage II session were greater to the object (or its representation) previously reinforced in Stage I when the responses to each presentation were compared for individual subjects using Mann-Whitney $U$ tests (Siegel, 1956). These results are summarized in Table 3.

While the groups all showed similar rates of learning in Stage $I$, as shown by a nonsignificant difference in days to criterion among groups (one-way analysis of variance, $F=.08$ ), Groups did differ in days to cri- terion in Stage II $(F=9.96, d f=3,12, p<.01)$. The birds in the drawing group took much longer to reach criterion than any of the other groups. In fact, two birds in the drawing group never reached criterion within the 21 days $(1,008$ trials) allotted for Stage II. Taken together with the previous analyses, this result suggests that the discrimination of line drawings was seen as a problem completely unrelated to and much more difficult than the Stage I problem.

Discrimination of objects from their pictures (Stage III) was rather easily accomplished and did not differ as a function of type of picture. Days to criterion ranged from 3 to 5 , including the 3 criterion days; percentage of total response to the reinforced display on the last criterion day ranged from 88.1 to 100 . Nonsignificant $F$ tests were obtained for both sets of data ( 0.92 and 1.50 , respectively; $d f=2,9, p>.05$ ).

\section{EXPERIMENT II}

In order to support the conclusion that the effects seen on the first transfer day in Experiment I were not merely a function of a change in the procedure (i.e., an effect of the reversed reinforcement contingency) and to show equivalence between objects and pictures in another way, the four birds from the object group in Experiment I were retrained to criterion on the Stage II transfer problem (a discrimination between the original solid objects for those birds) and then were transferred without reversal to black-and-white photographs. Note that these birds were naive with respect to pictures. Retraining was necessary as several days on which the birds were not trained intervened between the end of their use in Experiment $I$ and the beginning of Experiment II; retraining, however, amounted to little more than the 3-day criterion period.

\section{Method}

Subjects, apparatus, stimulus materials, and procedure were as described above, except that the reinforcement contingency in effect during initial training was not reversed when the transfer to photographs was tested. Transfer data were collected on the first transfer day, which occurred 3 to 5 days after the beginning of retraining.

In addition to the transfer test, to examine possible effects of extraneous cues from the apparatus or procedure, this group of birds was tested with the base block and back panels but not the objects or photographs on the 10 th day of training. That is, training with the solid objects was continued, after the single transfer session with photographs, to 10 days; on the 10th day, the objects were removed and responses were recorded to the bare base blocks manipulated in the same way as the displays had been the previous 9 days.

\section{Results}

A high degree of discrimination, in the direction of positive transfer, was found on test days for all birds, indicating a high degree of equivalence between solid objects and black-and-white photographs, as MannWhitney $U s$ computed on the numbers of responses to each presentation of each display for each bird on both 
the last discrimination criterion day and the transfer day yielded $p$ values ranging from 0.0005 to 0.000001 .

The results of the test for the effects of extraneous cues can be seen in the change in percentage of total responses to the reinforced display between the 9 th day and the 10th day for the four birds, respectively: 99.1 to $49.1,98.1$ to $47.9,95.6$ to 48.7 , and 99.1 to 44.3 . The obvious conclusion is that extraneous cues from the apparatus and procedure played a negligible role in the discriminations observed.

\section{EXPERIMENT III}

The possibility that any or all the discriminations were based on cues from the apparatus or procedure, particularly since displays were changed by hand, was further tested in this experiment, in which an explicit attempt was made to train a discrimination on the basis of nonvisual information from the apparatus.

\section{Method}

Four of the birds trained in groups other than the object group in Experiment I were nonsystematically selected for this experiment. Apparatus was as described above. The transparent key, however, was covered with translucent masking tape, permitting the birds to see the lights in the tunnel as they went on and off but not allowing any sight of events occurring inside the tunnel. Simulus materials consisted of the base blocks and back panels from Stage I of Experiment I with the objects removed to avoid any possibility of visual information from the display being used.

Procedure was as described under General Methods. Training continued for an arbitrary 21 days $(1,008$ trials), or until the criteria for discrimination were reached. Thus, the sequences of trials and the noises of the apparatus were exactly the same as in Experiments $I$ and II, but a visual discrimination was impossible.

\section{Results}

None of the birds had required more than 9 days to master the Stage I problem in Experiment I, yet no bird reached criterion on the Experiment III discrimination within the 21-day test period, although performance improved somewhat over the training period. Judging from these results, it seems clear that apparatus or procedure cues are, at best, an unlikely explanation for the discrimination and transfer seen in Experiments I and II.

\section{DISCUSSION}

It was predicted that pigeons trained to discriminate two solid objects would spontaneously transfer that discriminative response to black-and-white photographs, line drawings, and white-on-black silhouettes of those objects from their pictorial representations. The predictions were confirmed in all instances except for transfer to line drawings. A second experiment showed positive transfer between objects and photographs. Data for individual subjects supported group results. A third experiment tended to rule out extraneous cues as a basis for the discriminations observed.
These results show that, in contradiction to some conceptions of pictorial perception, learning specific to pictures, e.g., in the form of direct or mediated object-picture association, is not a necessary condition for all pictorial perception. Further, this inference is based for the first time on a study of nonprimate behavior. One now feels confident that, as a general rule, perception of at least some forms of pictorial representation does not depend as a general rule on learning to "read" a picture, as Goodman (1968), for example, asserts is necessary. This must be so, since, transfer occurred in an organism which had had no opportunity to learn to "read" pictures. Optical identity, in the sense of point-to-point correspondence, cannot explain the observed transfer either, since the objects were readily discriminated from their pictorial representations even when transfer was manifest.

The only apparent remaining competing theory of perception of pictures, based on equivalence of structure in light (information) reflected from both the solid objects and the pictorial representations of the objects, is the theory of Gibson (1971), which, it may be argued, predicts both nonhuman and human perception of pictures and also predicts object-picture discrimination. This is possible because the bases for both transfer and discrimination are in the light available from the object and pictorial displays, independent of any observer. The absence of transfer to line drawings, on the other hand, which the Gibsonian theory presumably would have predicted, raises the possibility that more than one theory may be needed to explain the whole of pictorial perception, a point that Hagen (1974) has also made. More research with line drawing displays, with human and animal subjects, is needed to provide clarification of this issue.

It should be noted that, while the present results strongly suggest that pigeons are capable of picking up information about objects from pictures, the kind of information used has not been determined. The informational basis for the transfer found in the present work will be a focus for future research. Further investigation of pigeons' responses to line drawings would be of interest both in this regard and from the point of view provided by the theoretical analysis of Kennedy (1974), who proposed that lines can represent a variety of features in the world, including edges, contrast changes, dihedral angles, boundaries of objects, and others. Zimmermann and Hochberg (1971) have suggested that rhesus monkeys respond appropriately to lines as representations of object edges, and Hochberg and Brooks (1962) found that a child, specifically denied the opportunity to learn what lines might represent, nevertheless recognized line drawings of familiar objects quite well. The possibility exists, then, that pigeons' failure to transfer a discriminative response from objects to line drawings is a manifestation of a species difference in perceptual ability. Kennedy's (1974) question, "what is a line and what can it represent," needs to be 
asked in a comparative way and points to the possibility that some objects (or features of objects) and not others may be representable to pigeons (and perhaps other untested species) as line drawings, i.e., that an interaction between object and mode of representation exists and is important. Klopfer's (1971) failure to obtain object-picture transfer in an imprinting situation further suggests the broader possibility that perception by nonhuman subjects is a function of the object represented, the mode of representation, task variables, and organismic peculiarities in completely unknown combinations.

Along this line, some limitations on the present results should be pointed out. Certainly a limited range of the great number of representation types was used, and only half the transfer relation was, in fact, tested. It would be of interest to see whether, as Zimmermann and Hochberg (1971) seem to imply, object-to-picture transfer in fact means the same thing as picture-toobject transfer. This point has not been tested in detail in any species.

Pictorial materials have been used in a variety of widely cited experiments with nonhuman subjects (Butler, 1961; Herrnstein \& Loveland, 1964; Hess, 1950; inter alia), often with the (implicit) assumption that the animal subjects were responding to the pictures used in the same way they would respond to the objects or events represented. As has been pointed out here, there is very little direct support for such an assumption. Although the present work tends to justify that assumption, additional research remains to be done before that assumption's validity is beyond doubt.

\section{REFERENCES}

Butler, R. A. The responsiveness of rhesus monkeys to motion pictures. Jourmal of Genetic Psychology, 1961, 98. $239-245$.
Davenport, R. K.. \& Rogers, C. M. Perception of photographs by apes. Behaviour. 1971, 31, 318-320.

Fellows, B. J. Chance stimulus sequences for discrimination tasks. Psychological Bulletin, 1967, 67, 87-92.

Gibson. J. J. The information contained in pictures. Leonardo, 1971. 4, 27-35.

Goodman, N. Languages of art. New York: Bobbs-Merrill, 1968.

Hagen. M. A. Picture perception: Toward a theoretical model. Psychological Bulletin, 1974, 81, 471-497.

Herrnstein, R, J., \& Loveland, D. H. Complex visual concept in the pigeon. Science, 1964, 146, 549-551.

Hess, E. H. Development of the chick's responses to light and shade cues of depth. Journal of Comparative and Physiological Psychology, 1950, 43, 112-122.

HochberG, J. C., \& Brooks, V. Pictorial recognition as an unlearned ability: A study of one child's performance. American Journal of Psychologv. 1962. 75. 624-628.

KENNEDY, J. M. A psychology of picture perception: Images and information. San Francisco: Jossey-Bass, 1974.

KLopfer. P. H. Imprinting: Determining its perceptual basis in ducklings. Journal of Comparative and Physiological Psychology, 1971. 75, 378-385.

Lubow. R. E. High-order concept formation in the pigeon. Journal of the Experimental Analysis of Behavior. 1974. 21, 475-483.

MilleR. R. J. Cross-cultural research in the perception of pictorial materials. Psychological Bulletin. 1973, 80, 135-150.

SIEGEL, S. Non-parametric statistics. New York: McGrawHill. 1956.

WINER. B. J. Statistical principles in experimental design. New York: McGraw-Hill. 1962.

ZimmermanN. R. R.. \& HochBerG, J. C. Responses of infant monkeys to pictorial representations of a learned visual discrimination. Psychonomic Science, 1970, 18. 307-308.

ZimmermanN. R. R.. \& Hochberg. J. C. The facilitation of picture discrimination after object discrimination in the neonatal monkey and probably vice versa. Psychonomic Science, 1971, 24, 239-241. 